Article

\title{
The Kindness of Strangers: Exploring Interdependencies and Shared Mobilities of Elderly People in Rural Japan
}

\author{
Fuyo (Jenny) Yamamoto * and Junyi Zhang \\ Graduate School for International Development and Cooperation, Hiroshima University, Kagamiyama 1-5-1, \\ Higashi-Hiroshima, 739-8529, Japan; E-Mails: yamamotojenny@hiroshima-u.ac.jp (J.Y.), zjy@hiroshima-u.ac.jp (J.Z.) \\ * Corresponding author
}

Submitted: 11 August 2017 | Accepted: 20 September 2017 | Published: 28 December 2017

\begin{abstract}
For over forty years, most residents in rural areas of Japan have relied on private vehicles to meet their mobility needs. Today, however, the rapid ageing of the population, coupled with low birth rates and migration of young people to urban areas, is posing a variety of new transport challenges. Most notably, the proportion of drivers to non-drivers is getting smaller. This means that non-drivers who relied on family and neighbours for trips in the past, as well as elderly residents who give up their licenses, have fewer people to drive them. Current policy debates tend to focus on technological "solutions", and underestimate the complex social, cultural and inter-personal relationships which underlie transport dependencies in these environments. Using a qualitative semi-structured survey, the current study explores the current mobilities of older people living in a small rural district in Shimane Prefecture, Japan. The resulting analysis reveals how cultural attitudes and social norms affect the ways in which older people manage their mobilities.
\end{abstract}

\section{Keywords}

ageing; cultural attitudes; driving; elderly; Japan; mobility; transport; older people; rural transportation; social exclusion

\section{Issue}

This article is part of the issue "Regional and Urban Mobility: Contribution to Social Inclusion", edited by Janet Stanley (University of Melbourne, Australia) and John Stanley (University of Sydney, Australia).

(C) 2017 by the authors; licensee Cogitatio (Lisbon, Portugal). This article is licensed under a Creative Commons Attribution 4.0 International License (CC BY).

\section{Introduction}

As recently noted by the United Nations, "Population ageing-the increasing share of older persons in the population-is poised to become one of the most significant social transformations of the twenty-first century, with implications for nearly all sectors of society" (United Nations, 2015). Not only is the share of the population over the age of 65 rising in relation to the rest of the population of most industrialized countries, but the absolute number of elderly people is increasing rapidly as life expectancies increase. These three trends-the growing share, the rising number, and the increasing longevity of people-are bringing issues related to the mobilities of older people to the centre of public policy debates in high and middle-income countries.

Japan is at the forefront of these demographic transitions. In 2015, the number of people aged 65 or more exceeded 33 million, or a little over one in four persons; of this 33 million, close to 10 million were aged 80 or more (Government of Japan, 2017a). At present, Japan has the longest life expectancy in the world, averaging 86.8 years for women and 80.5 years for men in 2015 (WHO, 2017). Meanwhile, falling birth rates and conservative immigration policies resulted in negative population growth between 2010 and 2015, the first such contraction since the population census began in 1920 (Government of Japan, 2017b). Rural areas, particularly in prefectures outside of 
major metropolitan areas, have been ageing and facing depopulation at faster rates than urban areas. ${ }^{1}$

These trends are having profound effects across all dimensions of Japan's economy and society, not least in the area of transport. For example, mobility and access issues relating to older people are featured with increasing regularity in the national media, with three issues in particular attracting public attention: the safety record of "senior drivers" (officially 65 years or older); the growing number of "public transport white spaces" ("koukyo kōtsu kuuhaku chiiki", or areas where residents have no access to public transport); and "shopping refugees" ("kaimono nanmin", or people who can't access shops for food and other daily necessities).

These issues are not particularly new (Mosely, 1979), nor unique to Japan (Mollenkopf, Marcellini, Ruoppila, Széman, \& Tacken, 2005). But what makes this particular moment in Japan's rural transport history critical is that it marks the convergence of several concurrent and interrelated factors. One is that local governments are under intense budgetary pressure to reduce their support for the few public transport services which are still running in remote and rural areas. Another is that local shops in rural areas are on the verge of disappearing altogether, as shopkeepers themselves are ageing and face difficulties in sustaining their businesses due to economic, health and logistical reasons, such as the inability to drive to wholesale markets to restock their shops. But perhaps most significantly, the first "baby boom" generation (born shortly after the Second World War) are now entering the $75+$ age group and are expected to stop driving in the next ten years. This is significant not only because the absolute number of non-drivers will increase, but because the majority of these "new" non-drivers are men who have provided escorting services for their wives and parents for the last forty to fifty years. The impact of their "retirement" from driving, therefore, has wider repercussions than simply the cessation of driving for these individuals.

In this regard, the government, as well as local communities and social service providers, have been trying a variety of different transport and social service delivery models to support the mobility of older people and to guarantee them access to their daily needs. For example, the government retains some regulatory control over private bus companies to ensure the operation of routes deemed essential for severely depopulated areas. In 2006, it amended the national Road Transport Vehicle Law to allow greater flexibility in their operations (for example, flexible routing and scheduling) (Akiyama
\& Yoshida, 2009). As a result, over 1,250 municipalities (including villages and towns) were running community bus services by 2015 (out of a total of 1,718), while about 360 had started demand-responsive shared taxi services (Government of Japan, 2017c). ${ }^{2}$ In May 2016, the government also began a pilot test of an Uber-type taxi service in a remote area of Kyoto prefecture, followed by another pilot in August 2016 in a remote area of Hokkaido prefecture (Nikkei, 2017).

The academic community is also actively researching older people's mobilities. Not only in Japan but in other countries as well, there has been a notable rise in the number of academic papers on the mobility and access needs of elderly people since around 2000 (see Chikaraishi, 2017). However, the literature is dominated by quantitative studies which tend to treat the elderly as a fairly homogenous group with homogenous transport needs. Furthermore, the majority of papers focus on the individual mobilities of older people, rather than shared (or intra-household) mobilities. This may be because they mainly draw on data from North America, Europe and Australia, where the majority of older people live in single generation households, unlike the case of Japan where many older people still live in multigenerational households (Government of Japan, 2017a). Another common assumption is that older people prefer driving to other modes of transport (Alsnih \& Hensher, 2003), but as noted above, historically driving has been a highly gendered skill in Japan, and even today most women over the age of 75 use a combination of private vehicles (mainly as passengers), public transport, and non-motorized modes (walking and cycling).

In order to better understand the mobilities of older people in rural Japan, it is worth suspending some of these assumptions and asking the people themselves about how they perceive their own mobilities. In this regard, the current article presents the findings of a qualitative study on the mobilities of older people living in Nijo, a small rural district located in Shimane Prefecture, western Japan. The study looked at older people's corporeal mobilities outside of home, and explored three basic questions: first, why do older people travel?; secondly, how do they travel?; and thirdly, how do they perceive this travel?, particularly their dependence on other people for mobility. The research framework drew on the literature on rural transport; the mobilities of older people; transport-based social exclusion and accessibility; and to a limited extent, the "new mobilities" paradigm.

The article is structured as follows. The next section presents a review of selected literature on the mobilities

\footnotetext{
${ }^{1}$ Administratively, Japan has 47 prefectures which are divided into "shi" (city) and "gun" or "choson" (rural counties) (according to population size and density); "gun" and "choson" are further divided into towns and villages. However, these categories do not necessarily reflect "urban" and "rural" characteristics (many city boundaries, for example, encompass rural districts). The term "rural" as used in the present article is closest to Rath's (2009) functionalist definition of rural Japan, meaning "those areas which are less populated and developed, where the chief occupation is agriculture or forestry, and where these livelihoods and the environment encourage the inhabitants to live cohesively with one another and with nature" (Rath, 2009).

2 Community buses are defined as those passenger bus services which are independently planned and operated under the authority of local governments. Most are run by professional transport service providers. Demand-responsive shared taxi services are usually small vans carrying up to 11 people (including the driver); are reserved in advance; and do not have to follow a fixed route (Government of Japan, 2017c).
} 
of older persons. The third section describes the research site, while the fourth section describes the methodologies used. The fifth section presents the findings, while the article ends with concluding remarks and suggestions for future research.

\section{Review of the Literature}

As noted above, the mobilities of older people have captured the attention of researchers from a variety of transport-related disciplines. Most "traditional" studies focus on differences in travel patterns between older people and other age groups (trip distances, number of trips, trip complexity, and so on), or look at differences among older people, such as by gender ( $\mathrm{Su} \&$ Bell, 2012), age (Alsnih \& Hensher, 2003), or activity (Hahn, Kim, Kim, \& Ulfarsson, 2016). Researchers have also been interested in how age-related changes in physical and cognitive capacities affect the ability to utilize transport technologies, particularly driving. Meanwhile, geographers, urban planners and environmental gerontologists are concerned with how age-related changes, particularly health and physical attributes, interact with the built-environment to affect the ability of older people to negotiate infrastructure or access public transport (e.g., Lin et al., 2014).

Although there is some evidence to the contrary (see Alsnih \& Hensher, 2003, on the recently-retired), there is a general consensus that ageing is associated with a loss of mobility. A growing number of studies therefore focus on the consequences of this loss of mobility. Many studies show, for example, that loss of mobility (for example, as a result of driving cessation) leads to lower participation in out-of-home activities, which in turn is associated with lower (subjective) assessments about quality of life and well-being (Banister \& Bowling, 2004; Metz, 2000; Mollenkopf et al., 2005; Nordbakke \& Schwanen, 2013; Spinney, Scott, \& Newbold, 2009; on driving cessation see, for example, Marottoli et al., 2000).

Researchers on social exclusion have also studied the relationship between mobility and the subjective wellbeing of older people (for example, Stanley, Hensher, Stanley, \& Vella Brodrick, 2011), but take a broader view by linking transport disadvantage to other forms of disadvantage (Delbosc \& Currie, 2011; Lucas, 2011; Stanley, 2011). By linking mobility outcomes to social outcomes, social exclusion researchers firmly situate the issue of access to transport within a broader social policy agenda (McDonagh, 2006; Stanley, 2011). In this regard, the social exclusion framework offers tremendous potential for analyzing the mobilities of older people because it appreciates the many different factors affecting individuals' access to transport (Church, Frost, \& Sullivan, 2000), and could potentially accommodate the different scales of mobility which are affected by ageing (Webber, Porter, \& Menec, 2010).

However, in the quest for "policy relevant research" and generalizable results, the main theoretical push within the social exclusion literature appears to have been the development of indicators to measure transport disadvantage and social exclusion (Geurs \& van Wee, 2004; Lucas, 2011; Pyrialakou, Gkritza, \& Friker, 2016; Schönfelder \& Axhausen, 2003). Thus, despite calls for a greater use of individual level data to understand social exclusion (Grieco, 2003; Kamruzzaman \& Hine, 2011; Preston \& Rajé, 2007), most studies treat "the elderly" as one of several groups at risk of exclusion. Studies which analyze social exclusion and mobility in rural areas also share this tendency (for example, Kamruzzaman \& Hine, 2012; Smith, Hirsch, \& Davis, 2012). Furthermore, these studies do not look in detail at how older people interact with other people (such as family members), or how they themselves may be choosing to be excluded from what would be considered "normal" social activities. The few exceptions are mostly qualitative studies, such as Shergold and Parkhurst (2012) who conducted a mixed methods study on self-reported social exclusion of older people in Southwest England and Wales and found that "accepting lifts" had a number of negative aspects, such as having to adjust to the lift-giver's timetable, or privacy issues when going to medical appointments. This points to a gap in the literature, because if the request for mobility support is mediated "by their perception of what is possible or reasonable to expect", then it is likely to influence people's travel decisions (Farrington \& Farrington, 2005).

Meanwhile, some behavioural transport researchers have explored intra-household interactions from the perspective of joint activity participation, joint travel arrangement, household resource allocation, task and time allocation, and role specification (Zhang, Timmermans, \& Borgers, 2004). Most studies focus on the transport behaviours of couples or parents providing escorting services to children, with only a few looking specifically at older people (Zhang \& Fujiwara, 2006), and one looking at the impact of elderly care on care-givers' time use behaviour (Chikaraishi, Zhang, \& Fujiwara, 2012). While these studies help to show how people's transport patterns are affected by other people within the same households, they don't explain how these behaviours are negotiated, nor the complex social and cultural norms which frame these shared mobilities.

In this regard, the current study aims to add to the small but growing body of literature which uses qualitative and mixed methods approaches to understand travel behaviour (see review by Mars, Arroyo, \& Ruiz, 2016). It has similar objectives to the study of rural transport in the Republic of Ireland by Ahern and Hine (2012), in that it is motivated by a desire to first better understand the actual mobilities of older people in rural areas of Japan, and second to better understand how older people themselves perceive their mobility options. To capture both of these aspects, this research employed two types of coding: the first used a provisional coding list based on the seven types of factors identified by Church et al. (2000) which potentially affect the mobility of socially excluded people, and the second used values coding to try to cap- 
ture the particular attitudes and values underlying older people's mobilities. The findings reported in this article focus specifically on those related to the shared mobilities of older people.

\section{Description of Research Site}

Nijo is located 18-20 km from the center of Masuda City (population circa 47,000 in 2017), Shimane Prefecture, and consists of five subdistricts (Asaka, Kamikuro- dani, Kurosu, Katuragahira, and Kashibara) (Figure 1). Like other rural areas of Japan, its population has been declining steadily over the past few decades, as has the number of households (Figure 2). As of early 2017, it had an estimated population of around 500 people living in 210 households, with subdistrict populations ranging from about 200 in Kamikurodani, to only 25 in Asaka.

In line with national trends, Nijo has also steadily aged, with an estimated $46 \%$ of the population now over the age of 65 (Figure 3). As can be seen, women outnum-

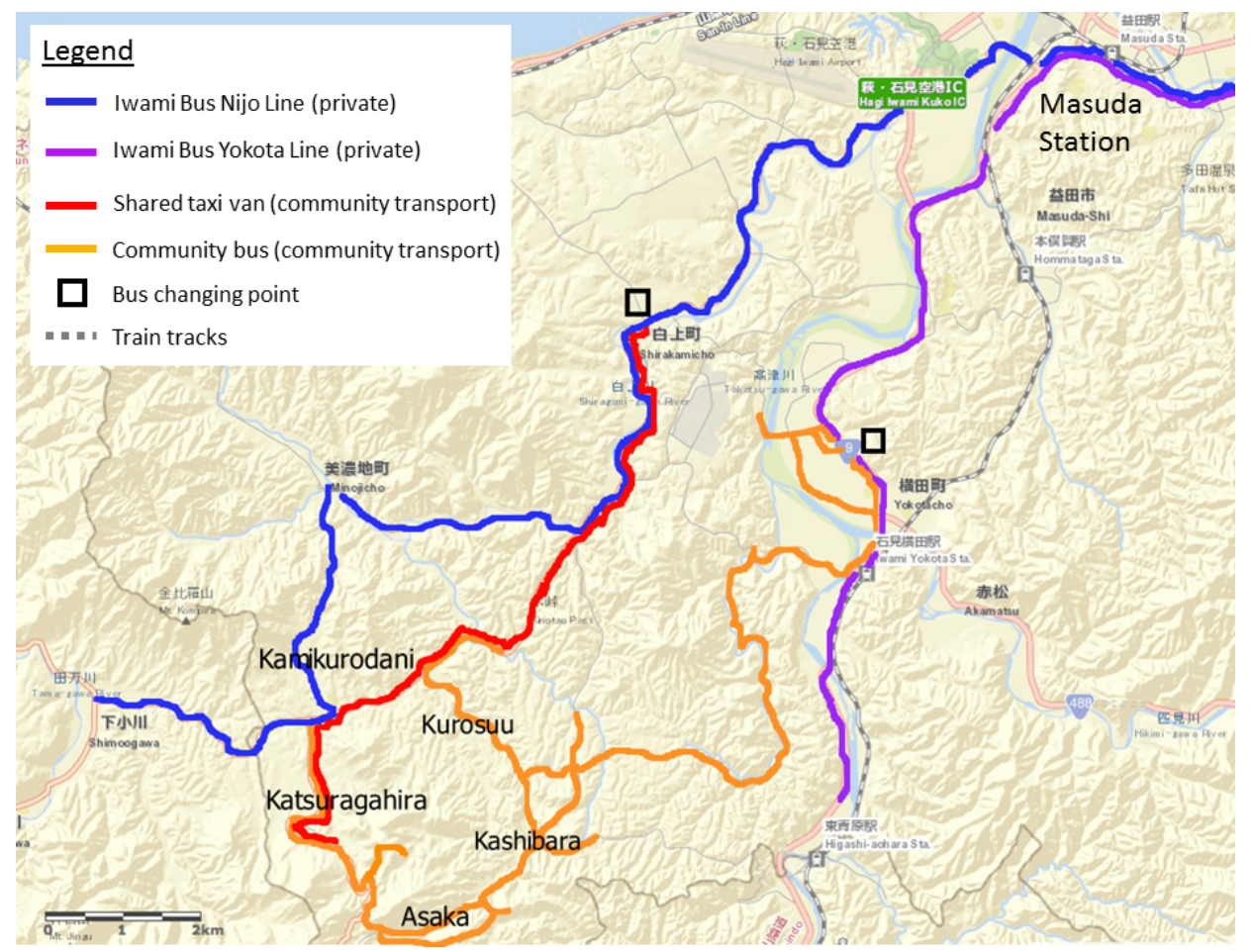

Figure 1. Map of Bus links between Nijo and Masuda City Centre. Source: Authors using ArcGIS basemap (Esri Japan, Esri, HERE, Garmin, INCREMENT P, NGA, USGS (c) Esri Japan).

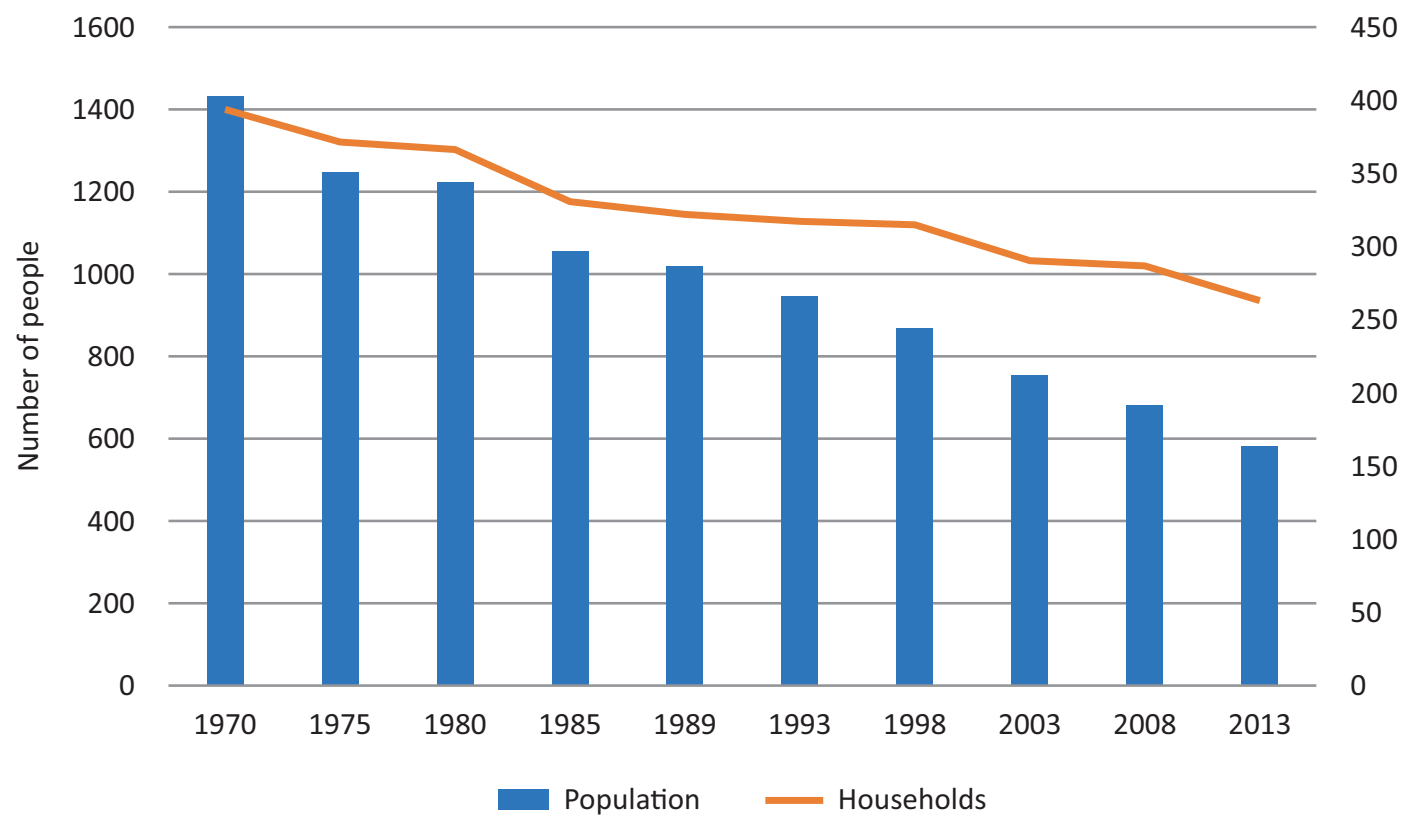

Figure 2. Population and number of households in Nijo, Masuda City. Source: Nijo Community Association (2015). 


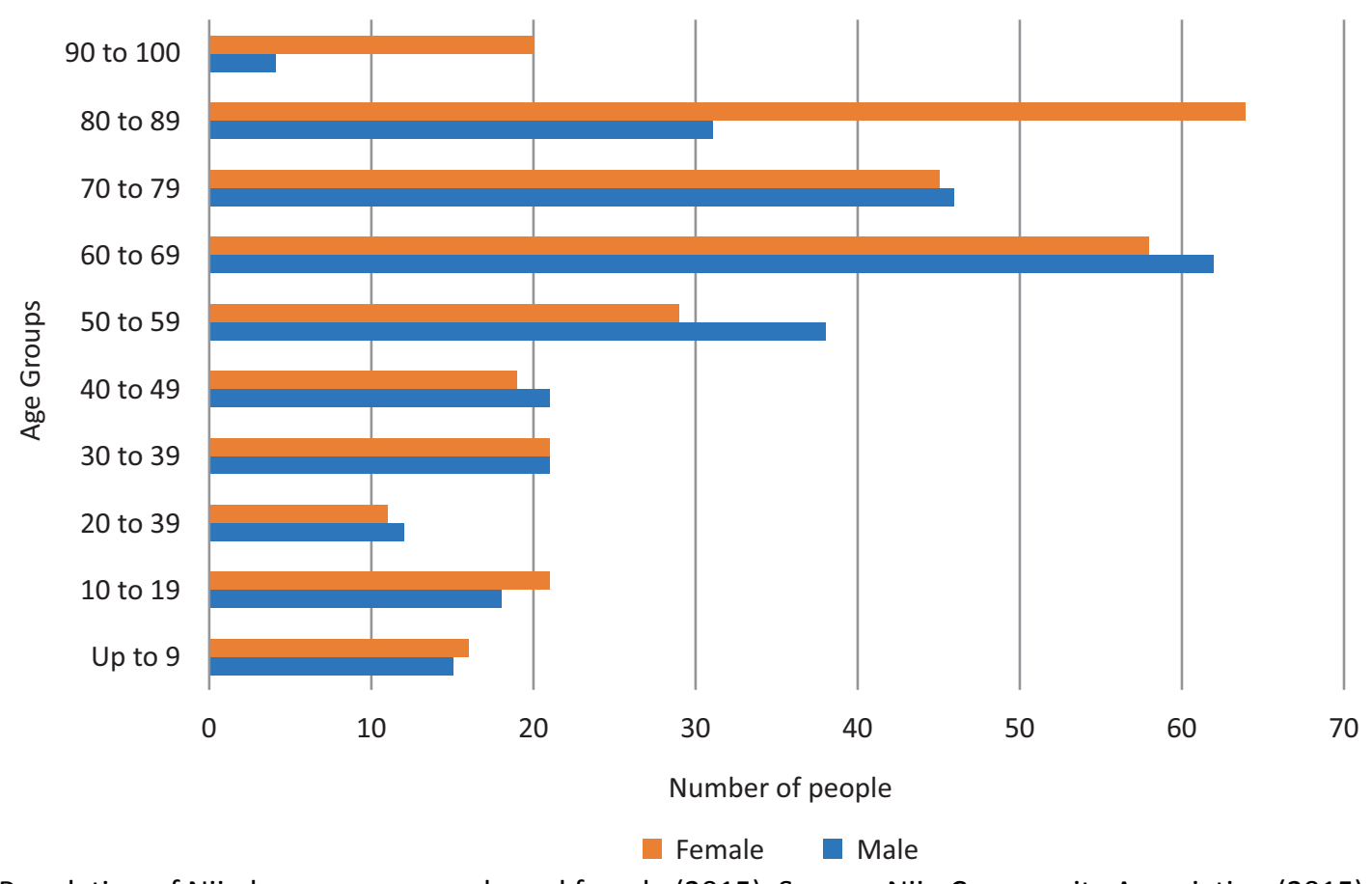

Figure 3. Population of Nijo by age group, male and female (2015). Source: Nijo Community Association (2015).

ber men in the 80-89 and 90-99 categories. According to a district-wide survey conducted in 2014, 1 person, 2 people or 3-5 people households constituted roughly one third of the population respectively, while 30 households reported having more than six people (Nijo Community Association, 2014). The majority of working age people commute to Masuda and surrounding areas by car for work, while the older population are mostly engaged in agriculture (rice and vegetable farming) near their homes.

The area is considered mountainous, with road elevations in Nijo ranging from 50 to over 300 meters above sea level. One prefectural road and several local roads link the five subdistricts to each other and to Masuda City. Most households are located along or within 10 metres from some kind of road. Within subdistricts, it is common to find several houses clustered together, but distances between houses can range from a few metres to 100 (or more) metres, depending on the subdistrict. For example, some houses in Kamikurodani are clustered around the old shopping street, where a few shops, the community centre, post office, Japan Agricultural Cooperatives' office, and the junior high and elementary schools are located, but in other subdistricts households are scattered over a wider area, separated by paddy and vegetable fields.

Apart from households where no one drives, most households (even single person) own more than one vehicle. This is because residents prefer to use "light" trucks (with engines up to $660 \mathrm{cc}$ ) for carrying agricultural products and tools, and drive "ordinary" cars for other business and social excursions. A private bus company provides a service five or six times a day through two of the subdistricts to Masuda (where the hospitals, supermar- kets, and DIY stores are located), while the three other subdistricts are served by community transport services one or two times per day (depending on the day). Community transport passengers have to transfer to the private bus once en-route, and again at Masuda station to go to the hospitals. Another community bus service runs within the district once a week, so that residents can access the local health clinics and post office.

\section{Research Design and Methodologies}

\subsection{Interview Protocol}

After an initial two-week period of direct observation, a semi-structured interview protocol was drawn up. Face to face interviews with older residents (65 and above) were then conducted over a four-week period in May/June 2017. The protocol consisted of three core questions, namely:

1) why do you travel? (for what purpose, which included where they travel to);

2) how do you travel? (travel mode, with whom they travel);

3) how do you feel about your travel? (particularly how they feel about arranging travel; how they feel about asking other people for lifts; and who they would call for transport in an emergency).

As it was expected that most interviewees did not drive, the research design also included interviews with family members and neighbours who supported older people's mobilities in order to triangulate the data. However, there was a general reluctance to invite the re- 
searcher back to meet other family members, and requests for telephone numbers of family members were politely declined. It was also logistically difficult to secure formal interviews with family members or neighbours as most of them worked in Masuda and came back in the evening. Family members and neighbours were therefore engaged in informal conversations (for example, at community events outside of home). The researcher also had informal conversations with other people in the community, including shop-keepers, community leaders, local government staff, visiting nurses, and the local hairdresser.

\subsection{Sampling Method}

The sampling methods used were purposeful and snowball, partly to ensure that all five subdistricts were represented, and also because there is a general feeling of mistrust of outsiders amongst older Japanese people, who have become the target of money swindling scams set up by organized crime groups in recent years. The initial contact for the first six interviewees was through the personal introduction of community leaders. Another five interviewees were met at social events, while two further women were approached without introductions. Snowball sampling was used to identify other older people who could be interviewed. This led to four additional introductions, bringing the total to 17 persons. At this point the data appeared to reach saturation point and data collection (formal interviews) was stopped (Fusch \& Ness, 2015).

\subsection{Coding Processes}

Fourteen formal interviews were recorded and transcribed (three respondents did not want to be recorded), and then two coding processes were used to analyse the interviews. As a first step, factors associated with transport-based social exclusion as identified by Church et al. (2000) were used as the basis of a provisional coding list (Saldaña, 2016). In brief, these factors are 1) physical exclusion; 2) geographical exclusion; 3) exclusion from facilities; 4) economic exclusion; 5) time-based exclusion; 6) fear-based exclusion; and 7) space exclusion (see Church et al., 2000, for a description of these factors). In the course of doing the first round of coding, several additional issues emerged, leading to a revision of the original list (Table 1), and the data was recoded. A second round of coding using values coding (Saldaña, 2016) was then conducted on the original transcripts to try to capture cultural attitudes and social norms influencing how people perceived their transport options, including asking other people for lifts.

\section{Findings}

\subsection{Profile of Respondents}

The initial analysis separated people by gender, driving status (non-drivers and drivers), and household composition (living with drivers; living with non-drivers; living alone) (Table 2). The ages of respondents varied, with 69 being the youngest and 92 being the oldest. All respondents could walk, though one recently had an operation and was not able to walk very far. Of the total 17 respondents, 14 were women and 3 were men.

As it was relatively unusual for women to get driving licenses until the 1970s, it was not surprising to find that 13 out of the 14 female interviewees had never driven a car in their life. In the past, these women relied on their husbands or public transport to travel. The one exception was the youngest woman (69), who had gotten a driving license following the death of her husband some thirty years before, but who had given it up recently after a traffic accident. One woman drove a scooter for short distances from her home to the Community Center and bus stop. The two women who lived with non-drivers had husbands who had recently given up their licenses following (non-traffic) accidents. All three men (aged 79, 85 and 92) still drove on a daily basis.

Table 1. List of final provisional codes (adapted from Church et al., 2000).

\begin{tabular}{ll}
\hline Type of factor & Description \\
\hline Physical factors & $\begin{array}{l}\text { Physical barriers, such as vehicle design, affect access to transport services } \\
\text { (this also includes personal attributes which affect a person's abilities to manage } \\
\text { such barriers) }\end{array}$ \\
\hline Geographical factors & Distance or topographical factors affect access to transport services \\
\hline Economic factors & Costs of travel affect travel frequency or limit access to facilities \\
\hline Time-related factors & $\begin{array}{l}\text { Length of travel time; demands on time, such as household duties and institutional } \\
\text { and coupling constraints (Hägerstrand, 1970) affect use of transport services }\end{array}$ \\
\hline Fear or safety factors & Fears for personal safety affect people's use of public spaces and transport services \\
\hline Information-related factors & Lack of, or unintelligible, information affects access to transport services \\
\hline Social networks and cultural & Social networks, social norms and cultural factors affect people's access to or use \\
factors & of transport services \\
\hline
\end{tabular}


Table 2. General profile of respondents.

\begin{tabular}{|c|c|c|c|c|c|c|c|c|}
\hline & \multicolumn{2}{|c|}{ Gender } & \multirow{2}{*}{$\begin{array}{l}\text { Driver living } \\
\text { with non-driver }\end{array}$} & \multirow{2}{*}{$\begin{array}{l}\text { Driver living } \\
\text { alone }\end{array}$} & \multirow{2}{*}{$\begin{array}{l}\text { Non-driver } \\
\text { living with } \\
\text { driver(s) }\end{array}$} & \multirow{2}{*}{$\begin{array}{l}\text { Non-driver living } \\
\text { with non-driving } \\
\text { spouse }\end{array}$} & \multirow{2}{*}{$\begin{array}{l}\text { Non-driver } \\
\text { living alone }\end{array}$} & \multirow[t]{2}{*}{ Subtotal } \\
\hline & $\mathrm{F}$ & $\mathrm{M}$ & & & & & & \\
\hline Kurosuu & 4 & 1 & & 1 & 2 & 1 & 1 & 5 \\
\hline Kashibara & 1 & 1 & 1 & & & & 1 & 2 \\
\hline Kamikurodani & 4 & & & & 3 & 1 & & 4 \\
\hline Katsuragahira & 3 & 1 & & 1 & & & 3 & 4 \\
\hline Asaka & 2 & & & & & & 2 & 2 \\
\hline Total & 14 & 3 & 1 & 2 & 5 & 2 & 7 & 17 \\
\hline
\end{tabular}

\subsection{Why Older People Travel-And How}

Most interviews began with the question "why do you travel?", followed by "how do you travel?" (Table 3). As all of the male respondents drive, the following discussion is focused on the responses of the interviewed women.

\subsubsection{Travel for Health}

All interviewees responded that their primary reason to travel was to visit hospitals, health clinics or dentists in Masuda. Women living with drivers used a mix of private (family) and bus services. A common pattern was to be driven by their children (or sons and daughters-inlaw), who dropped them at the hospital on their way to work in the morning, and to take the bus back on their own. This was because they didn't want to wait until the evening to return home. Women not living with drivers normally used the bus. Several also said that their (nonresident) children occasionally drove them if they had time to come pick them up, or were visiting during the weekends or holidays.

\subsubsection{Travel for Shopping}

The second most common reason for travel was shopping. However, almost all respondents said that they rarely go to Masuda for the sole purpose of shopping (unless accompanying family), but might do so in conjunction with a hospital visit. Many respondents emphasized that they try to do their shopping locally. The reason for shopping locally, however, was not only due to the geographic proximity of shops, but also out of loyalty to the shop-keepers: a common statement heard was "as long as there are local shops, (we should) do our shopping there", usually followed by "I've been obliged to Mr. X (the shop-keeper) for a long time" ("naganen $X$ san ni osewa ni nattekimashita").

The women also ask family (both in-household and non-resident) to buy products which are not available locally or are too large or heavy to carry on the bus. Several women noted that they were visited by family members on a regular basis (between every week to every few months, depending on where family members lived). For example, one woman showed me a large stock of food

Table 3. Purpose and mode of travel.

\begin{tabular}{|c|c|c|c|}
\hline & \multirow{2}{*}{$\begin{array}{l}\text { Non-driver living with family or } \\
\text { near family } \\
\text { Regular }\end{array}$} & \multicolumn{2}{|c|}{$\begin{array}{l}\text { Non-driver living alone/with non-driving } \\
\text { spouse/not near family }\end{array}$} \\
\hline & & Regular & Occasional \\
\hline Health (regular visits) & $\begin{array}{l}\text { Family } \\
\text { Bus }\end{array}$ & Bus & Family (if visiting) \\
\hline Health (emergency) & $\begin{array}{l}\text { Family (if available) } \\
\text { Ambulance } \\
\text { Neighbours }\end{array}$ & $\begin{array}{l}\text { Ambulance } \\
\text { Neighbours }\end{array}$ & Family (if visiting) \\
\hline Shopping (food) & $\begin{array}{l}\text { Family } \\
\text { Bus (in conjunction with } \\
\text { hospital visit) }\end{array}$ & $\begin{array}{l}\text { Bus (in conjunction with } \\
\text { hospital visit) }\end{array}$ & Family (if visiting) \\
\hline Shopping (other goods) & Family & & $\begin{array}{l}\text { Family (if visiting) } \\
\text { Friends (if invited) } \\
\text { Neighbours (if invited) }\end{array}$ \\
\hline $\begin{array}{l}\text { Community and social } \\
\text { activities }\end{array}$ & Family & $\begin{array}{l}\text { Bus, Members of community } \\
\text { (such as Niko Niko Kai) }\end{array}$ & \\
\hline
\end{tabular}


and drinks which had been bought by her son after her doctor had told her not to walk too much; he (or his son) came every weekend from Hiroshima, about 2.5 hours drive away, to restock provisions.

A few respondents mentioned that if asked by a neighbour whether they needed anything from a particular store, they sometimes requested specific items. For example, one woman said that she sometimes asked her neighbour to pick up seedlings from the garden centre, but only if he asked her first. She would never initiate the request.

\subsubsection{Travel for Social Activities}

Two women mentioned that they sometimes take part in the weekly gatherings of "ground golf" organized by the "Old People's Club", which is within walking distance of their houses. But most said that at their age, they rarely went out to see friends or for social purposes. When asked whether they would go out more if transport could be arranged, none of the women directly said that they wanted to. Most saw going out, particularly on long trips, as a burden and/or bothersome activity ("mendokusai"). Women in their 80s especially stressed that they didn't want to travel far or go on overnight trips anymore, with one explaining that "if something should happen, it will be a big inconvenience ("meiwaku") for my family."

However, when discussing one of the respondents with a younger woman (who was not in the sample and is a friend through their interest in sewing), she noted that "whenever I ask her (the older woman) if she would like to go out, for example to the haberdashery shop, she jumps and says: "I'll go, l'll go!". So whether these women would go out more often, if invited, is difficult to gauge from this study.

In this regard, it is worth noting that in rural areas of Japan, older women are not in the habit of "socializing" in the Western sense of visiting other people's houses or going out to eat. Rather, they take part in occasional community activities. Several respondents, for example, mentioned that they participated in the monthly gathering of the Niko Niko ("smiling") Club, where the "younger" old people (mostly retired and in their 60s and early 70s) prepare lunch and group activities for the older people.

\subsection{Provisional Coding Results: Selected Factors Affecting the Shared Mobilities of Older People}

\subsubsection{Geographical Factors}

For women living with drivers, geographical factors did not seem important when requesting lifts from family members. However, this could be because respondents' primary purpose of travel was to attend medical appointments in Masuda (where most people commute to for work), and because children are also expected to care for their parents (see Section 5.4.1 below). Women living alone or with non-drivers were unwilling to call their families for lifts to go to Masuda (or unable to when their children lived in Tokyo or Osaka) and preferred to use the bus. Given that it is a hilly area, it was expected that respondents would mention topographical factors (for example, difficulty in accessing bus stops), but those who used the bus did not mention this aspect, except to say that in the winter they had to be more careful.

\subsubsection{Time-Related Factors, Including Coupling and Institutional Constraints}

Most respondents who used the community bus noted that it took a long time. This is because the route traverses the whole district and involves changing to the private bus, which makes for a journey time of 60 to 90 minutes, compared to driving directly, which takes only 20 to 30 minutes. Meanwhile, women who lived with drivers were conscious that they were "asking" their children for a lift, and therefore adjusted their travel around their children's work schedule, even if it meant that they had to wait longer at the hospital before their appointments.

However, time at the station, where the private buses returned from, was seen as a bigger inconvenience than the journey time for both women living with drivers and those without drivers. For example, when early morning appointments were finished, they sometimes waited more than two hours at Masuda Station to catch the return bus. Some women used this time for shopping, eating lunch, or chatting with people at the bus stop, but one woman complained that she couldn't walk due to a bad hip and just sat at the station. In another case, the woman explained that she had arranged to meet three different doctors during her last visit to the hospital, but ran out of time and had to cancel one appointment in order to catch the return bus. In this regard, the institutional constraints imposed by the schedules of hospital appointments and return buses were of greater concern than the actual time taken to travel.

\subsubsection{Social Networks and Cultural Factors}

Apart from family excursions, the main social activity involving mobility was participating in the monthly Niko Niko Club. However, invitation to this Club is limited to older people living in the precinct of the former elementary school (which has been closed for more than ten years). The husbands of the "younger" women who organize the club (and who are mainly in their 70s) provide chauffeuring services for the older people and take pride in this role: one man noted that "without us, these gatherings couldn't take place". In contrast, most women who live outside of this precinct said that they had generally stopped attending outside social activities; one said that she was no longer interested because such activities were "for the younger people". 


\subsection{Values Coding Results: Attitudes towards Shared Mobilities and Interdependencies}

After the first round of coding, it became clear that social norms and cultural attitudes have a significant bearing on older people's mobilities, particularly whether people ask others for lifts. In order to address this point, a second round of values coding was conducted which tried to explore the values and attitudes underlying the responses.

\subsubsection{Interdependencies between Older People and Family Members}

In general, there was a strong sense of "using my own legs for as long as possible", a sentiment shared by both women and men. However, in the case of medical appointments, women living with drivers did not mind asking their family for lifts because it is expected that children will take care of their parents. At the same time, these women seemed aware of their dependence on their children. Those living with their children were engaged in household tasks such as cooking, cleaning, looking after their grandchildren, gardening and farming. One woman (89) explained that she woke every day at 4:30 to prepare breakfast for her son and daughter-in law (in their late 50s/early 60s) and granddaughter (early 20s). So she did not mind "using" ("tsukau") her family to go to the hospital when they were off from work.

Some women, both living with drivers and not living with drivers, also said they were sometimes invited out "for a drive" by family members. For example, several mentioned that their children or grandchildren had taken them out for a meal on Mother's Day, while another woman said that one of her grandsons took her and her husband (also over 80 years old) out for a "drive" every month.

\subsubsection{Interdependencies between Older People and Non-Family Members}

A common theme which emerged from the interviews was the reluctance of older people to feel obliged or beholden to other people. Asking non-family members for help, when a person has the option of asking family members, is also generally viewed as being socially unacceptable. Even for medical emergencies, all respondents said that they would first ask their family members or call an ambulance rather than ask their neighbours for help. For example, one woman who lived alone described how a few months ago, she had been in so much pain that she could barely crawl, but instead of calling for an ambulance, a neighbour or her younger sister (who lives in Masuda), she stayed in bed for one week and ate cold rice which she had happened to cook the night before. When asked why she hadn't contacted anyone for help, she said she didn't want to cause any worry ("shinpai sasetakunakatta kara"). Meanwhile, another woman said that in an emergency: "I call a taxi. Everyone is busy, (so) if I call a taxi, I can ask them without constraint ("kiganenaku", or without being afraid of troubling someone else)"

However, several respondents said that they might ask their neighbours in an emergency if they could not contact their family. For example, one woman recounted that, when her husband had tripped and fallen on the ground near their house one month before, she had immediately rushed to a neighbour's house for help. A few women also acknowledged that as they got older, they needed to learn to accept help from others. For example, while recounting that on a recent trip back from hospital, the taxi driver had very kindly carried her husband into the house, one woman said: "(We) have to be obliged to others really, or we can't live when we get old" ("konotoshidewa osewa ni naranyara, yatteikaremasen").

In this regard, an interesting example of mutual exchange was given by the leaders of the Niko Niko Club, who explained that the monthly gatherings were a kind of "duty fulfillment" ("ongaeshi") to "all these people who took care of us when we were young" ("kawaigattekureta hito"). In this situation, the older people seemed comfortable "to be indebted" to this younger generation, many of whom they had known when they were growing up.

\subsubsection{Interdependencies between Older People and Other Older People}

One of the most surprising findings from the interviews was the extent to which older people were assisting other older people with their mobility needs. A particularly striking example was the 79 year-old man who drove his physically disabled younger brother (in his late 60s), five days a week, from their house to the bus stop where he was picked up for his job at a social welfare organization (which grows vegetables for sale). Another example was the youngest (69 year-old) woman who had become something of a spokesperson for people using community transport, for example negotiating changes to the route to make it easier for one of her neighbours to catch the bus.

On the other hand, older people are also aware of the safety risks associated with older drivers. When asked whether anyone in her neighbourhood helped her to travel, one woman said:

Yes, Mr. A. always stops and offers a ride when he sees me walking-But I would never get in a car with him. If you see a white light truck (the kind frequently used by older men in Nijo), think 'Danger!'

\subsubsection{Views of the Younger Generation}

Although it was not possible to formally interview the family members and neighbours involved in the mobilities of older people in Nijo, the informal conversations revealed some interesting insights. One was with the 
daughter of the 85 year-old man in this study. She noted that the issue of older drivers was a serious one (her father had had two "small" accidents in the last year, which he had not mentioned during his interview), but said it was difficult for drivers to offer lifts to people outside of their families "in case there's an accident". This view was shared by several other younger people; one said that she might give a lift to someone she knew well (for example, if she saw an older person waiting at the bus stop), but would probably not invite him or her otherwise.

The reluctance of older people to be "indebted" to others also makes it tedious for drivers to offer lifts, because the older people try to "repay" them in some way. Another younger woman noted that:

I often see my (elderly) neighbour (walking), but don't want to offer to help her because if I do, she then feels obliged to give me something or repay me in some way and it creates a lot of fuss. So I just don't say anything.

A staff member of the Community Centre (in her late 30s) brought up another issue, which was that she hesitated to offer lifts to older people because these days, the boundaries between "being kind" and "being overly concerned" ("osekkai", which is considered a nuisance) were increasingly blurred. She noted that:

It used to be when you offered help, $80 \%$ of the time it was considered a kindness and $20 \%$ of the time it was considered a nuisance, but today the ratio has changed and it is now $20 \%$ kindness and $80 \%$ nuisance.

\section{Concluding Remarks and Areas for Further Research}

The present study explored the mobilities of older people in a small rural district in western Japan using a qualitative approach, allowing older people to describe their mobilities and how they perceived their current mobility situation in their own words. While not representative of older people in Japan, the study provides some insights into the everyday mobilities of older people, particularly the influence of cultural attitudes and social norms on older people's willingness to depend on other people to meet their mobility needs.

The study confirmed that there was a significant difference in the mobility options of women and men; all male respondents still drove, while none of the women drove cars. The primary purpose of travel was to go to health facilities, while the travel modes of women varied between those living with drivers, and those living alone or with non-drivers. In both cases, respondents used a mixture of both private and public transport, although women living alone or with non-drivers had much fewer opportunities to avail of family members for lifts. The study further revealed the important role of older people (in this context, mostly men) in supporting other older people's mobilities.
To analyse how respondents perceived their mobility situation, the present study employed a combination of coding methods. The provisional coding list adapted from Church et al. (2000)'s factors influencing transportbased social exclusion served as a useful framework for analysing the interviews; not to judge whether respondents were "excluded" or not, but as a lens through which to consider the different issues affecting older people's mobilities in a comprehensive way. From the perspective of shared mobilities and interdependencies, time-related factors and cultural attitudes emerged as common themes. To explore these attitudes further, a second round of values coding was conducted, which found that while respondents did not mind asking family members for lifts to go to medical appointments, there was great hesitation when it came to asking neighbours. This seemed to stem from a widely shared reluctance to feel "indebted" to other people. Such a "psychological" barrier is probably related to how older people form/modify/maintain their social networks and communicate with members of these networks in their daily lives. This suggests the importance of community networks in promoting shared mobility in rural areas; measures encouraging such networks may therefore be helpful for supporting older people's travel needs.

While many studies are now being conducted on the mobilities of older people, they seem to underestimate the agency of these people in negotiating their mobilities. Despite being of advanced age, all of the respondents were still active in their own ways, and most seemed content with their current transport situation, regardless of their household composition. The nondrivers (women) were aware of inconveniences such as not being able to travel when and where one liked, but nobody complained as such: the general attitude was that "it can't be helped, this is the countryside". Furthermore, the findings also demonstrated the importance of contextualizing transport research to avoid the risk of imposing assumptions about travel behaviours which are not applicable. While not denying the importance of social activities for maintaining well-being, the findings suggest that the value attributed to mobility is heavily dependent on the cultural (and indeed, individual) context, as is the meaning of "independence" (Schwanen, Banister, \& Bowling, 2012). Several respondents expressed the desire to take care of their own mobilities ("use their own legs" as much as possible), but "dependence" on family members was not necessarily seen in a negative light; people appeared to have different roles, depending on their abilities and social expectations. This suggests that there is significant scope for further research drawing on the transport histories and cultural contexts of a wider variety of countries (Cresswell, 2016).

Given the important role of private vehicles in rural areas of Japan, any consideration of the mobility options of older people in rural Japan should include both private and public transport modes. In the absence of an expansion of public transport, the solution to securing mobil- 
ity in rural areas may lie in better uses of existing transport, such as new ways of sharing private cars. However, asking for lifts is a kind of travel behaviour choice which is mediated by cultural and social factors. This aspect of mobility has not been sufficiently dealt with in the literature. It is therefore suggested that further research is needed, both qualitative and quantitative, on culturally appropriate platforms or means of exchange (both monetary and non-monetary) to facilitate the asking for lifts.

Having discussed the findings, it should be noted that the study has several limitations. As noted in the literature review, many studies assume that ageing is associated with a loss of mobility, and many have found that older people associate the loss of mobility with a loss of welfare. Although a conscious effort was made to avoid bias throughout the research process, these assumptions informed the research design, such as the focus on dependencies during the values coding process. Some degree of researcher bias may have therefore affected the analysis of the interviews. Another limitation was that the general mistrust of outsiders raised significant barriers to accessing respondents. Though prior discussions and the involvement of community leaders facilitated introductions to older people, the researchers underestimated the challenges of arranging interviews with family and neighbours. Such interviews would have allowed the researchers to triangulate the data; any future study should consider more carefully how to integrate this aspect into the research design.

There is insufficient space in the present article to elaborate on culturally specific terms related to the "dependency" of the respondents or the underlying sentiments which are rooted in wider social values of Japanese society. Further consideration of these aspects is necessary to fully appreciate the motivations behind the travel behaviours of older Japanese people. In this regard, the time is ripe for "traditional" transport researchers to work more closely with qualitative researchers in other disciplines to develop a better understanding of the mobilities of older people in specific cultural contexts. For example, gerontological geographers are interested in the "spatialities of ageing", in terms of how older people themselves perceive these changes (embodiment), and how they manage them in relation to others (Schwanen, Hardhill, \& Lucas, 2012). Meanwhile, the "new mobilities" literature (Sheller \& Urry, 2006) has shown that qualitative methodologies are useful for understanding the different ways in which mobility, social relations and well-being interact (Hodgson, 2012). In view of the significant differences in the epistemological backgrounds of the various disciplines (Vannini, 2010), further theoretical work is needed to bridge these differences.

\section{Acknowledgements}

This research was made possible through the support of the Hiroshima University TAOYAKA Program for cre- ating a flexible, enduring, peaceful society, funded by the Program for Leading Graduate Schools, Ministry of Education, Culture, Sports, Science and Technology. The authors would like to thank the residents of Nijo who participated in the study and the reviewers for their comments.

\section{Conflict of Interests}

The authors declare no conflict of interests.

\section{References}

Ahern, A., \& Hine, J. (2012). Rural transport-Valuing the mobility of older people. Research in Transportation Economics, 34, 27-34.

Akiyama, T., \& Yoshida, I. (2009). Seikatsu shien no chiiki kokyou kōtsu [Regional Public Transport to Support Livelihoods]. Kyoto: Kakugai Publishing Company.

Alsnih, R., \& Hensher, D. A. (2003). The mobility and accessibility expectations of seniors in an aging population. Transportation Research Part A, 37, 903-916.

Banister, D., \& Bowling, A. (2004). Quality of life for the elderly: the transport dimension. Transport Policy, 11(2), 105-115.

Chikaraishi, M. (2017). Mobility of the elderly. In J. Zhang (Ed.), Life-oriented behavioral research for urban policy (pp. 267-291). Tokyo: Springer Japan.

Chikaraishi, M., Zhang, J., \& Fujiwara, A. (2012). Effects of nursing care on time use behaviour: A comparative analysis in Japan. Transportmetrica, 8(3), 181-208.

Church, A., Frost, M., \& Sullivan, K. (2000). Transport and social exclusion in London. Transport Policy, 7, 195-205.

Cresswell, T. (2016). Afterword-Asian mobilities/Asian frictions? Environment and Planning A, 48(6), 1082-1086.

Delbosc, A., \& Currie, G. (2011). Exploring the relative influences of transport disadvantage and social exclusion on well-being. Transport Policy, 18, 555-562.

Farrington, J., \& Farrington, C. (2005). Rural accessibility, social inclusion and social justice: Towards conceptualization. Journal of Transport Geography, 13, 1-12.

Fusch, P. I., \& Ness, L. R. (2015). Are we there yet? Data saturation in qualitative research. The Qualitative Report, 20(9), 1408-1416. Retrieved from http:// www.nova.edu/ssss/QR/QR20/9/fusch1.pdf

Geurs, K. T., \& van Wee, B. (2004). Accessibility evaluation of land-use and transport strategies: Review and research directions. Journal of Transport Geography, $12,127-140$.

Government of Japan. (2017a). Statistics Bureau, Ministry of Internal Affairs and Communications. Japan Statistical Yearbook 2017. Retrieved from http:// www.stat.go.jp/english/data/nenkan/66nenkan/in dex.htm

Government of Japan. (2017b). Chapter 2 "Population". Statistics Bureau, Ministry of Internal Affairs 
and Communications. Statistical Handbook of Japan, 2017. Retrieved from http://www.stat.go.jp/english/ data/handbook/index.htm

Government of Japan. (2017c). Part I. 2016 Transport Trends and 2017 Transport Policy [in Japanese]. Retrieved from http://www.mlit.go.jp/common/0011 86513.pdf

Grieco, M. S. (2003). Transport and social exclusion: New policy ground, new policy options. Paper presented at the 10th International Conference on Travel Behaviour Research, Lucerne.

Hägerstrand, T. (1970). What about people in regional science? Papers of the Regional Science Association, 24, 7-21.

Hahn, J., Kim, H., Kim, J., \& Ulfarsson, G. F. (2016). Trip making of older adults in Seoul: Differences in effects of personal and household characteristics by age group and trip purpose. Journal of Transport Geography, 57, 55-62.

Hodgson, F. (2012). Escorting economies: Networked journeys, household strategies and resistance. Research in Transport Economics, 34, 3-10.

Kamruzzaman, M., \& Hine, J. (2012). Analysis of rural activity spaces and transport disadvantage using a multimethod approach. Transport Policy, 19, 105-120.

Kamruzzaman, M., \& Hine, J. (2011). Participation index: A measure to identify rural transport disadvantage? Journal of Transport Geography, 19, 882-899.

Lin, T., Xia, J., Robinson, T. P., Goulias, K. G., Church, R. L., Olaru, D., ... Han, R. (2014). Spatial analysis of access to and accessibility surrounding train stations: A case study of accessibility for the elderly in Perth, Western Australia. Journal of Transport Geography, 39, 111-120.

Lucas, K. (2011). Transport and social exclusion: Where are we now? In M. Grieco \& J. Urry (Eds.), Mobilities: New perspectives on transport and society (pp. 207222). Abingdon: Routledge.

Marottoli, R. A., de Leon, C. F. M., Glass, T. A., Williams, C. S., Cooney, L. M., \& Berkman, L. F. (2000). Consequences of driving cessation: Decreased out-ofhome activity levels. Journal of Gerontology: Social Sciences, 55(6), 334-340.

Mars, L., Arroyo, R., \& Ruiz, T. (2016). Qualitative research in travel behavior studies. Transportation Research Procedia, 18, 434-445.

McDonagh, J. (2006). Transport policy instruments and transport-related social exclusion in rural Republic of Ireland. Journal of Transport Geography, 14, 355-366.

Metz, D. (2000). Mobility of older people and their quality of life. Transport Policy, 7(2), 149-152.

Mollenkopf, H., Marcellini, F., Ruoppila, I., Széman, Z., \& Tacken, M. (Eds.). (2005). Enhancing mobility in later life-Personal coping, environmental resources, and technical support. The out-of-home mobility of older adults in urban and rural regions of five European countries. Amsterdam: IOS Press.
Mosely, M. (1979). Accessibility: The rural challenge. London: Methuen.

Nijo Community Association. (2015). Healthy village making plan, 2015-2019 ["Genki na Mura Zukuri Puranu", 2015-2019].

Nijo Community Association. (2014). Nijo Community Association Face-to-Face Household Survey ["Nijochiku Machizukuri Tobetsu Kikitori Chousa Kekka Shuukeihyou"].

Nikkei. (2017, May 26). Rideshare, popular in depopulated areas but...progress still distant across Japan. Uber's domestic progress after 1 year [in Japanese]. Nihon Keizai Shinbun. Retrieved from https:// www.nikkei.com/article/DGXLASDZ26I2B_W7A520C 1TJ2000

Nordbakke, S., \& Schwanen, T. (2013). Well-being and mobility: A theoretical framework and literature review focusing on older people. Mobilities. doi:10.1080/17450101.2013.784542

Preston, J., \& Rajé, F. (2007). Accessibility, mobility and transport-related social exclusion. Journal of Transport Geography, 15, 151-160.

Pyrialakou, V. D., Gkritza, K., \& Friker, J. D. (2016). Accessibility, mobility, and realized travel behavior: Assessing transport disadvantage from a policy perspective. Journal of Transport Geography, 51, 252-269.

Rath, E. C. (2009). Rural Japan and agriculture. In W. M. Tsutsui (Ed.), A companion to Japanese history (pp. 477-492). Chichester: John Wiley and Sons Ltd.

Saldaña, J. (2016). The coding manual for qualitative researchers. London: Sage.

Schönfelder, S., \& Axhausen, K. W. (2003). Activity spaces: Measures of social exclusion? Transport Policy, 10(4), 273-286.

Schwanen, T., Banister, D., \& Bowling, A. (2012). Independence and mobility in later life. Geoforum, 43, 1313-1322.

Schwanen, T., Hardhill, I., \& Lucas, S. (2012). Spatialities of ageing: The co-construction and co-evolution of old age and space (editorial introduction to special issue). Geoforum, 43, 1291-1295.

Sheller, M., \& Urry, J. (2006). The new mobilities paradigm. Environment and Planning A, 38, 207-226.

Shergold, I., \& Parkhurst, G. (2012). Transport-related social exclusion amongst older people in rural Southwest England and Wales. Journal of Rural Studies, 28(4), 412-21.

Smith, N., Hirsch, D., \& Davis, A. (2012). Accessibility and capability: The minimum transport needs and costs of rural households. Journal of Transport Geography, 21, 93-101.

Spinney, J. E. L., Scott, D. M., \& Newbold, K. B. (2009). Transport mobility benefits and quality of life: A timeuse perspective of elderly Canadians. Transport Policy, 16, 1-11.

Stanley, J. (2011). Social exclusion. In G. Currie (Ed.), New perspectives and methods in transport and social exclusion research (pp. 27-44). Bingley, UK: Emerald 
Group Publishing Ltd.

Stanley, J. K., Hensher, D. A., Stanley, J. R., \& Vella Brodrick, D. (2011). Mobility, social exclusion and wellbeing: Exploring the links. Transportation Research Part A, 45(8), 789-801.

Su, F., \& Bell, M. G. H. (2012). Travel differences by gender for older people in London. Research in Transportation Economics, 34, 35-38.

United Nations. (2015). World population ageing 2015 (ST/ESA/SER.A/390). New York: United Nations.

Vannini, P. (2010). Mobile cultures: From the sociology of transportation to the study of mobilities. Sociology Compass, 4(2), 111-121.

Webber, S. C., Porter, M. M., \& Menec, V. H. (2010). Mobility in older adults: A comprehensive framework. The Gerontologist, 50(4), 443-450.
WHO. (2017). World health statistics 2017. Annex B. Tables of Health Statistics by country, WHO region and globally. Geneva: World Health Organization. Retrieved from http://who.int/entity/gho/publica tions/world_health_statistics/2017/en/index.html

Zhang, J., \& Fujiwara, A. (2006). Representing household time allocation behavior by endogenously incorporating diverse intra-household interactions: A case study in the context of elderly couples. Transportation Research Part B, 40, 54-74.

Zhang, J., Timmermans, H., \& Borgers, A. (2004). Model structure kernel for household task and time allocation incorporating household interaction and interactivity dependency. Paper presented at the 83rd Annual Meeting of Transportation Research Board, Washington, D.C.

\section{About the Authors}

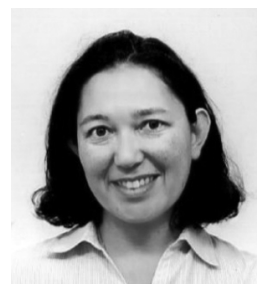

Fuyo (Jenny) Yamamoto is a doctoral student in Hiroshima University's TAOYAKA Program for creating a flexible, enduring, peaceful society. She previously worked on regional transport issues at the United Nations Economic and Social Commission for Asia and the Pacific, Bangkok, Thailand. Her research focuses on the everyday mobilities of people living in rural areas of developed and developing countries, and how these mobilities affect access to social services, education and employment opportunities.

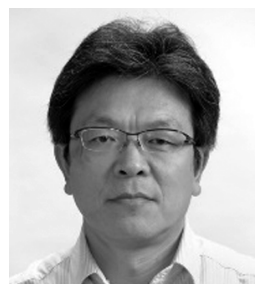

Junyi Zhang's research fields include urban and regional planning, transportation planning, traffic engineering, environment and energy policies, tourism policy, and health policy. He has developed various methodologies and applied them to analyse various issues related to the above fields from an interdisciplinary perspective, mainly based on behavioural and systematic approaches. In recent years, he has been especially promoting the life-oriented approach for cross-sectoral policies. He has published more than 370 refereed academic papers. 